\title{
Express Screening of Biological Objects Using Multisensor Stripping Voltamperometry with Pattern Recognition
}

\author{
I. I. Kolesnichenko', L. M. Balachova ${ }^{2}$, E. P. Kantarzhi2 \\ ${ }^{1}$ A. N. Frumkin Institute of Physical Chemistry and Electrochemistry RAS (IPCE), Moscow, Russia \\ ${ }^{2}$ Pirogov Russian National Research Medical University, Moscow, Russia \\ Email: kolesnichenko-ii@mail.ru
}

Received 11 May 2016; accepted 18 July 2016; published 21 July 2016

Copyright @ 2016 by authors and Scientific Research Publishing Inc.

This work is licensed under the Creative Commons Attribution International License (CC BY). http://creativecommons.org/licenses/by/4.0/

c) (i) Open Access

\begin{abstract}
Express diagnostics of biological objects is necessary for operational preliminary assessment of the condition of the patient. A method of recognition of differences between the norm and pathology is based on analysis of multidimensional patterns of the voltamperogram electrochemical test systems in Electronic formats "language", "electronic nose". The basis of such systems is the use of a set (matrix) sensor with completely different characteristics. A. N. Frumkin Institute of Physical Chemistry and Electrochemistry RAS (IPCE) developed a method for multidimensional stripping voltammetry, which allowed you to provide information on biological matter being investigated not as a number, as a response to a single dimension, and in the form of $\mathrm{N}$-dimensional image. Formats are implemented in the process of electrochemical studies of liquid or gaseous phase. Evaluating the closeness of the resulting image object under test with known samples is collected in a database. Examples of express diagnostics of glaucoma are with accordance of the results of the electrochemical research of blood serum.
\end{abstract}

\section{Keywords}

Express Screening, Biological Objects, Multisensor Stripping Voltamperometry, Glaucoma

\section{Introduction}

Of particular importance for the life of the organism is the constancy of composition of blood what is a liquid body basic. Its resilience has been studied in some detail the active reaction $(\mathrm{Ph})$, the ratio of electrolytes, glucose, and number of the formal elements and so on. Thanks to the intensive development of high-tech methods 
for research in the modern world, there are many new diagnostic capabilities. However, a large amount of information, which we expect to get, is often unavailable.

This raises the question about meaningful etiopathogenic using these techniques, especially in ophthalmology, because now there is no simple, informative and pathognomonic method for early diagnosis of the disease. Data for the study of the effectiveness of these techniques are not so much, informative of them at different ophthalmic pathology practically not studied, and this makes it difficult to determine their role in the survey. While medical and social importance of such pathology as glaucoma, myopia, retinopathy and AMD (agerelated macular degeneration) is so serious and indisputable that the relevance of the research that the actuality of the early detection of these diseases and their treatment becomes the No. 1 problem at the State Level. Despite the numerous methods of diagnosis and methods of treatment of the problem of blindness and a high level of disability from this ophthalmic pathology cannot be solved for many reasons.

This and later identification of the disease and asymptomatic period of development, the large labour input surveys and high cost. We offer an innovative method that does not require expensive and time, easy to use and does not require the patient to any effort as objects of research are assumed biological fluids (blood, urine, tear, etc.) or tissues taken during the operation.

A study carried out for the first time in ophthalmology. As a method of study are invited to use multisensory inversional (thick-film electrode) voltamperometry (IVA) to determine the status of the homeostasis of the organism as a whole, assessing whole blood or serum and local homeostasis, appreciating the tear fluid of the anterior Chamber of the eye and the vitreous. This allows you to trace the evolution of biological fluids organism depending on the evolution of the pathological process. Built because of express-diagnostics of biological fluids will be used for the preliminary assessment of various operational states of the organism. A method for recognition of multidimensional images derived from analysis of multisensory voltamperometry electrochemical test system in the format of "electronic nose". The format is done by electrochemical studies of liquid or gaseous phase liquid. Evaluating the degree of approximation of the resulting gaseous form liquid test image with known samples accumulated in a database. Conducted a pilot study of express-diagnostics of glaucoma according to the results of the electrochemical research of blood serum showed acceptable results. Fundamental scientific problem is to define mechanisms for the development of systemic and local changes in ophthalmopathology.

Effective diagnostics through early disease detection implies simple procedures for initial patient examination, thereby reducing time and labor costs.

In the line of the concept of metabolic profile [1], clinical chemistry is mostly concerned with analysis of body fluids. When conducting a comprehensive analysis of clinical chemistry is mainly limited to studies of the composition of the fluids of the human body [2]. A fundamentally new approach to the analysis of volatile compounds associated with the use of devices "electronic nose" [3]-[6]. When using the device "electronic nose" and "electronic tongue" [7]-[9] each analyzed substance corresponds to some characteristic pattern of feedback system that enables multidimensional discriminate against various substances (or mixtures of substances) by comparing them to images formed in advance $\mathrm{N}$-dimensional image database [10] [11]. A fairly complete list of models "electronic nose and electronic tongue" is presented in [12]-[14]. A number of foreign and domestic firms made bids for Annex developed analytical tools for evaluating the quality of foodstuffs [15] Wednesday, environmental monitoring [16], as well as for use in medical diagnosis [17]. In this study we investigated the possibility of application of electronic language "formats", "electronic nose" medical express diagnostics disease glaucoma.

In the latter case, certain conditions must be met. As a rule, volatile disease biomarkers are present in human breath at very low concentrations, whereas the concentrations of secondary gases, such as $\mathrm{CO}_{2}$ and water vapor, are high, killing the effect of the biomarkers in sensor responses. That is why pre-concentration of the sample is frequently required to extract useful signals. Such things increase both the time and cost of the analysis [18] [19]. It should be noted that there are many extraneous sources of volatile metabolites that can cause distortion of the “olfactory image" registered by E-nose. In practice it can significantly complicate the diagnosis of diseases [20].

This paper discusses the possibility of applying the E-tongue and E-nose technologies for early detection of glaucoma.

\section{Experimental Study}

\section{Materials and Methods}

The measurements have been done using the electrochemical multisensory analyzer developed at IPCE RAS 
(Moscow). The Analyzer consists of two blocks, connected by a USB cable (Figure 1):

- PC (laptop) with installed software, manipulator and USB cable;

- Measurement unit, consisting of electronic signal processing block, replacement electrodes and disposable electrodes.

On the lid there are three LEDs to indicate the respective electrochemical cells and to indicate the connection with the PC. Based on are threaded and socket connector for the replacement electrodes. On one of the sides of the hull removed the USB connector. The replacement electrodes is a card with the connector for the connection of electronic signal processing block and three connectors to install disposable, replaceable electrodes.

The replacement electrodes is a card with the connector for the connection of electronic signal processing block and three connectors to install disposable, replaceable electrodes.

The analyzer embodies a new approach using a solution containing various metal ions as an electrochemical test-system, the ions being able interact with organic substances to form complex compounds [21]-[23].

All known E-nose and E-tongue devices use a set of electrodes as sensors, therefore the reproducibility of characteristics of the multi-sensor systems is problematic, which affects the reliability and pattern recognition in a negative way. We propose enhancing the reliability and pattern recognition of our multi-sensor stripping voltamperometry method through the use of metal cations, dissolved in the background electrolyte, as sensors. One electrode is used to record voltamperograms by the stripping voltamperometry technique to obtain multidimensional patterns of analytes.

The test-system (background electrolyte) is a $0.05 \mathrm{M} \mathrm{KCl}$ solution containing the metal cations such as $\mathrm{Zn}^{2+}$, $\mathrm{Cd}^{2+}, \mathrm{Pb}^{2+}, \mathrm{Cu}^{2+}, \mathrm{Co}^{3+}, \mathrm{Hg}^{2+}$ as sensors. Thus an array of sensors is formed on one electrode allowing the device to be used as both E-tongue and E-nose.

The measurements have been done using planar electrodes (Autocom, Moscow), which represent polypropylene plates with working and auxiliary electrodes (carbon material) and silver-chloride reference electrode (Brown electrode) (Figure 2). The test-system solution, as background electrolyte, also serves as a concentrator for volatile impurities.

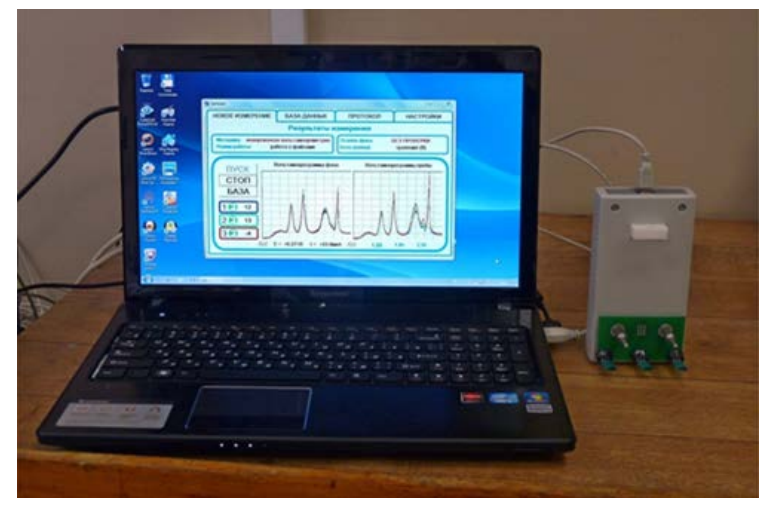

Figure 1. Multisensor stripping voltamperometry for studies of biological fluids.

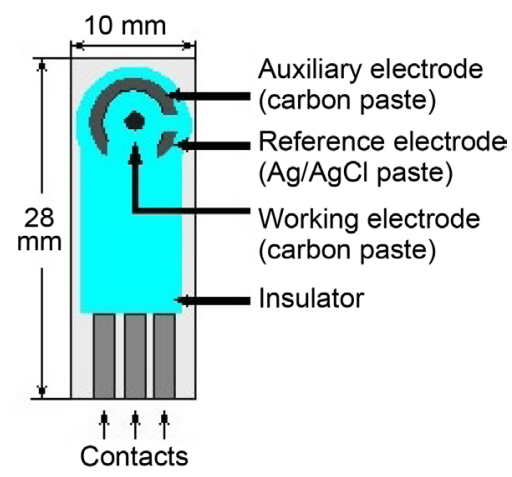

Figure 2. The scheme of a planar three-electrode system. 
The voltamperograms (sensor outputs) recorded by the method of stripping voltamperometry are characterized by specific features (Figure 3) and good reproducibility. The appearance of the voltamperograms change when different organic substances are added to the test-system. Each of the organic substances (or mixture of substances) produces specific changes, which allows their discrimination.

The experimental study used the serum samples provided by Pirogov Russian National Research Medical University in accordance with a scientific cooperation agreement.

\section{Statistical Data Processing}

\subsection{A Voltamperogram Is a Multidimensional Image of Primary Data}

The result of the operation is voltamperogram (Figure 3)—current dependence of electrode potential, changing on linear time (sweep rate capacity). The peaks correspond to oxidation of metals test systems. Digital values (453 points) coming into the program for further processing in the form of a file from which to retrieve the value of the current. A voltamperogram is divided into N-dimensional image, the amount of which depends on the complexity of the investigated system. Thus formed N-dimensional image object (Figure 4).

\subsection{Data Dimensionality Reduction}

The next step is to group processing correlated sensors into clusters by reducing the dimensionality of data with the subsequent allocation of $\mathrm{M}$ bulk of characterizing the cluster information. $\mathrm{M}$ varied to achieve maximum discriminatory ability.

There are many algorithms to reduce the dimensionality of the data, some of which were tested in the study: factor analysis, principal component analysis, cluster analysis, Fourier transform (Figure 5) [24].

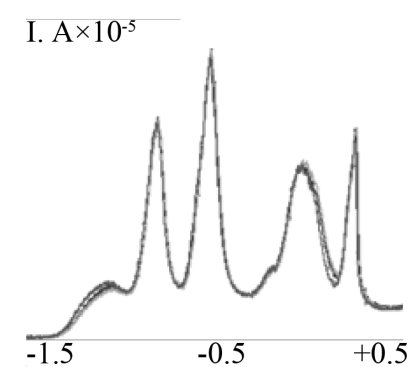

(a)

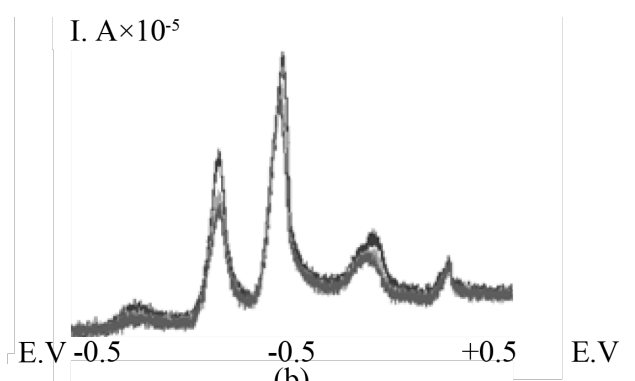

(b)

Figure 3. Voltamperograms (I-current in ampere, E-voltage in volt) of test-system solution (a) and test-system solution with blood serum of glaucoma patients (b).

\begin{tabular}{|c|c|c|c|c|c|c|c|c|c|c|}
\hline & $\begin{array}{c}1 \\
\text { Group }\end{array}$ & $\begin{array}{c}2 \\
\text { Var1 }\end{array}$ & $\begin{array}{c}3 \\
\text { Var2 }\end{array}$ & $\begin{array}{c}4 \\
\text { Var3 } \\
\end{array}$ & $\begin{array}{c}5 \\
\text { Var4 } \\
\end{array}$ & $\begin{array}{c}6 \\
\text { Var5 } \\
\end{array}$ & $\begin{array}{c}7 \\
\text { Var6 } \\
\end{array}$ & $\begin{array}{c}452 \\
\operatorname{Var} 451\end{array}$ & $\begin{array}{c}453 \\
\text { Var452 }\end{array}$ & $\begin{array}{c}454 \\
\operatorname{Var} 453\end{array}$ \\
\hline BOL\#1 & $\mathrm{BOL}$ & -1.26 & -1.31 & -1.28 & -1.22 & -1.22 & -1.05 & 4.41 & 4.52 & 4.49 \\
\hline BOL\#2 & OL & -1.35 & -1.35 & -1.33 & -1.33 & -1.37 & -1.25 & 4.17 & 4.18 & 3.98 \\
\hline BOL\#3 & BOL & -1.35 & -1.3 & -1.34 & -1.29 & -1.24 & -1.28 & 4.83 & 4.83 & 4.76 \\
\hline BOL\#1 & BOL & -1.53 & -1.44 & -1.44 & -1.47 & -1.39 & -1.11 & 6.61 & 6.7 & 6.78 \\
\hline BOL\#2 & OL & -1.55 & -1.51 & -1.5 & -1.51 & -1.46 & -1.2 & 6.95 & 6.98 & 7.02 \\
\hline BOL\#3 & BOL & -1.67 & -1.58 & -1.56 & -1.64 & -1.51 & -1.48 & 7.1 & 7.18 & 7.02 \\
\hline BOL\#1 & BOL & -1.33 & -1.27 & -1.24 & -1.2 & -1.24 & -1.01 & 6.47 & 6.57 & 6.62 \\
\hline BOL\#2 & BOL & -1.44 & -1.53 & -1.46 & -1.43 & -1.39 & -1.32 & 5.84 & 5.98 & 5.75 \\
\hline BOL\#3 & BOL & -1.47 & -1.39 & -1.5 & -1.41 & -1.39 & -1.17 & 6.1 & 6.15 & 6.06 \\
\hline ZDOR\#1 & ZDOR & -1.67 & -1.68 & -1.58 & -1.54 & -1.59 & -1.4 & 7.91 & 8.11 & 7.8 \\
\hline ZDO & ZDOR & -1.83 & -1.81 & -1.78 & -1.76 & -1.73 & -1.59 & 7.59 & 7.75 & 7.62 \\
\hline ZDOR\#3 & ZDOR & -1.76 & -1.85 & -1.82 & -1.9 & -1.8 & -1.63 & 7.21 & 7.37 & 7.05 \\
\hline 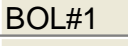 & $\mathrm{BOL}$ & -1.28 & -1.22 & -1.21 & -1.16 & -1.05 & -0.83 & 6.71 & 6.71 & 6.73 \\
\hline BOL\#2 & $\mathrm{BOL}$ & -1.44 & -1.34 & -1.37 & -1.33 & -1.29 & -1.16 & 6.47 & 6.43 & 6.45 \\
\hline
\end{tabular}

Figure 4. Part of the table containing the database voltamperograms. 


\subsection{Discrimination Algorithm}

The purpose of discriminatory analysis is attributing the object under study to a certain group/class by its characteristics in an optimal way, minimizing expected losses and the probability of misclassification. Discriminatory analysis, as part of statistical multi-parameter analysis, comprises methods for classification of multidimensional objects through the use of available training samples.

Training samples were obtained by measuring parameters of known analytes to be subsequently stored in the database.

A similarity measure is the square of the Mahalanobis distance, which shows how close the object is to the centroids of the groups of known samples in the space of canonical roots.

The results of the discrimination are visually presented as a graph in the space of the first and second canonical roots, the known analytes being depicted as clouds of points surrounded by ellipses and the sample under study as a point.

Thus, the discriminatory analysis allows the objects under study to be classified by a set of group/class attributes (Figure 6).

The values of current were recorded in the database, assigned to one of three groups: "ZDOR”, "BOL”, or

\begin{tabular}{|l|r|r|r|r|}
\hline \multirow{2}{*}{ Value number } & \multicolumn{5}{|c|}{$\begin{array}{l}\text { Egenvalues of correlation matrix, and related statistics ( } \\
\text { Active variables only }\end{array}$} \\
\cline { 2 - 5 } & Egenvalue & $\begin{array}{c}\text { \% Total } \\
\text { variance }\end{array}$ & $\begin{array}{l}\text { Cumulative } \\
\text { Egenvalue }\end{array}$ & $\begin{array}{c}\text { Cumulative } \\
\%\end{array}$ \\
\hline 1 & 284.9301 & 62.89848 & 284.9301 & 62.8985 \\
\hline 2 & 75.9272 & 16.76098 & 360.8573 & 79.6595 \\
\hline 3 & 36.8073 & 8.12523 & 397.6646 & 87.7847 \\
\hline 4 & 14.2213 & 3.13936 & 411.8859 & 90.9240 \\
\hline 5 & 8.1646 & 1.80234 & 420.0505 & 92.7264 \\
\hline 6 & 5.5298 & 1.22071 & 425.5803 & 93.9471 \\
\hline 7 & 4.3181 & 0.95321 & 429.8984 & 94.9003 \\
\hline 8 & 4.1290 & 0.91147 & 434.0273 & 95.8118 \\
\hline 9 & 3.5759 & 0.78939 & 437.6033 & 96.6012 \\
\hline 10 & 2.4218 & 0.53462 & 440.0251 & 97.1358 \\
\hline 11 & 2.0498 & 0.45249 & 442.0749 & 97.5883 \\
\hline 12 & 1.4422 & 0.31838 & 443.5172 & 97.9067 \\
\hline 13 & 1.3176 & 0.29085 & 444.8347 & 98.1975 \\
\hline 14 & 1.2006 & 0.26504 & 446.0354 & 98.4626 \\
\hline 15 & 0.9087 & 0.20060 & 446.9441 & 98.6632 \\
\hline
\end{tabular}

Figure 5. The eigenvalues of the first 15 factors.

\begin{tabular}{|l|r|r|r|r|r|r|r|r|}
\hline & \multicolumn{7}{|l|}{$\begin{array}{l}\text { Factor scores, based on correlations (blood_Trainer.sta in BLOOD_Trainer.stw) } \\
\text { Labelling variable: Group }\end{array}$} \\
\cline { 2 - 9 } Case & Group & Factor 1 & Factor 2 & Factor 3 & Factor 4 & Factor 5 & Factor 6 & Factor 7 \\
\hline BOL\#1 & BOL & 0.65503 & 1.12580 & -0.37819 & 1.77452 & 1.18666 & 0.54981 & 0.17731 \\
\hline BOL\#2 & BOL & 0.78504 & 1.43239 & -1.44866 & -0.04120 & 0.89001 & 0.17012 & -0.58410 \\
\hline BOL\#3 & BOL & 0.39240 & 0.60703 & -1.12983 & 0.90085 & 0.09819 & 0.33136 & -0.83847 \\
\hline BOL\#4 & BOL & -0.53017 & -0.26588 & 0.64814 & 1.28736 & 0.54569 & -0.61166 & -0.12137 \\
\hline BOL\#5 & BOL & -0.76457 & -0.68873 & 0.37542 & 0.25688 & 0.14737 & -1.91715 & -0.24536 \\
\hline BOL\#6 & & -0.75562 & -0.51187 & 0.44335 & -0.34811 & -0.50994 & -0.74973 & -1.27856 \\
\hline BOL\#7 & BOL & -0.41092 & -0.51003 & 0.88730 & 1.56210 & 0.65995 & 0.76310 & 1.14169 \\
\hline BOL\#8 & BOL & -0.23511 & 0.57831 & -0.99792 & -0.58957 & -0.02161 & -0.39101 & 0.09414 \\
\hline BOL\#9 & BOL & -0.31470 & 0.49278 & -0.86069 & -0.41968 & 0.07809 & -1.03757 & 1.12134 \\
\hline ZDOR\#1 & ZDOR & -1.62661 & 0.66686 & 1.37642 & -1.74224 & 2.24687 & -0.37388 & 0.30051 \\
\hline ZDOR\#2 & ZDOR & -1.40926 & 0.69932 & 0.91624 & -1.96703 & -0.21992 & 0.45718 & -1.22224 \\
\hline ZDOR\#3 & ZDOR & -0.89332 & 1.11197 & 1.47748 & -1.90155 & 0.38965 & 1.09832 & -1.48747 \\
\hline BOL\#11 & BOL & -0.54886 & -1.79631 & -0.85137 & 1.11919 & 1.23853 & 0.54796 & 0.49565 \\
\hline BOL\#12 & BOL & -0.50258 & -1.67607 & -0.33024 & 0.70587 & -0.57121 & 0.88418 & -1.98282 \\
\hline
\end{tabular}

Figure 6. The result of the principal component analysis-value factors (the part). 
“TEST”, indicating presumably healthy patients, or glaucoma patients, or the test-system (reference sample), respectively. Three independent measurements of the blood serum of each testee are stored in the database, too.

The statistics software package Statistica 6.0 was used for data processing.

\section{Preparation of Samples}

\subsection{E-Tongue Technique}

Using the electrodes coated with 50 microliters of the test-system solution, a voltamperogram was recorded at a cathodic metal deposition potential of $-1.55 \mathrm{~V},-1.45 \mathrm{~V}$, and $-1.35 \mathrm{~V}$ versus the silver-chloride electrode with subsequent potential sweep to $+0.3 \mathrm{~V}$. The test-system was then removed from the electrodes with filter paper. 5 microliters of a blood serum sample was preliminarily diluted with the test-system solution up to 1/2000 concentration in the Eppendorf test tube $(\mathrm{V}=2 \mathrm{~mL})$. The test tube was then sealed hermetically and incubated for $15 \mathrm{~min}$ at room temperature. The resulting sample $(50 \mathrm{mcL})$ was applied onto the electrodes, after which measurements were done.

\subsection{E-Nose Technique}

Covered with $50 \mathrm{mcL}$ of blood serum, a disc of porous material with a diameter of $8 \mathrm{~mm}$ (Blue ribbon filter) was put into the cap of the Eppendorf test tube $(\mathrm{V}=2 \mathrm{~mL})$ to serve as a source of odor. Prior to analysis, $100 \mathrm{mcL}$ of the test-system solution was injected into the test tube with the source of odor in order to concentrate volatile substances. The test tube was then sealed and placed in a thermostat at $40^{\circ} \mathrm{C}$ for $40 \mathrm{~min}$. During this time, the test-system solution was saturated with vapors of volatile metabolites from the sample of blood serum. Then it was analyzed by the inversion voltamperometry technique in the same way as by the E-tongue technique.

\section{Results and Discussion}

\subsection{E-Tongue Technique}

Figure 3 shows the voltamperograms recorded during analyses of both the test-system solution 1) and the test-system solution with glaucoma patients' samples of blood serum 2). All voltamperograms for the blood serum samples of healthy persons are alike, being different quantatively. The blood serum samples of 14 glaucoma patients and 6 presumably healthy people were used to estimate the possibility of discrimination based on the E-tongue technique.

Each patient's sample was measured three times, the data averaged. A table of the data comprises 14 rows marked with "BOL" and 6 rows marked with "ZDOR". A total of 20 calculations were done, each having the grouping mark ("BOL" or "ZDOR") of the current sample nulled, thus rendering the sample "unknown" for discriminatory analysis.

Figure 7 shows the results of discriminatory analysis in the form of 2D distribution of the samples of presumably healthy people and glaucoma patients. The two groups of points are surrounded by ellipses with a confidence probability of 0.95 .

The results of statistical analysis show that 3 out of 6 serum samples of presumably healthy people and 9 out of 14 serum samples glaucoma patients are discriminated correctly, which amounts to $50 \%$ and $64 \%$, respectively.

\subsection{E-Nose Technique}

Figure 8 shows voltamperograms obtained during analysis of test-system samples enriched with volatile compounds of blood serum from presumably healthy testees and glaucoma patients.

The discrimination ability was tested using the blood serum samples of nine glaucoma patients and five presumably healthy ones. Each patient's sample was measured three times. Consequently, a table of the initial data comprises 27 rows marked with "BOL" and 15 rows marked with "ZDOR". A total of 42 calculations were done, each having the grouping mark of the current sample nulled, thus rendering the sample "unknown" for discriminatory analysis.

Figure 9 shows the results of discriminatory analysis in form of 2D projection of samples of presumably healthy testees and glaucoma patients. The two groups of points are surrounded by ellipses with a confidence 


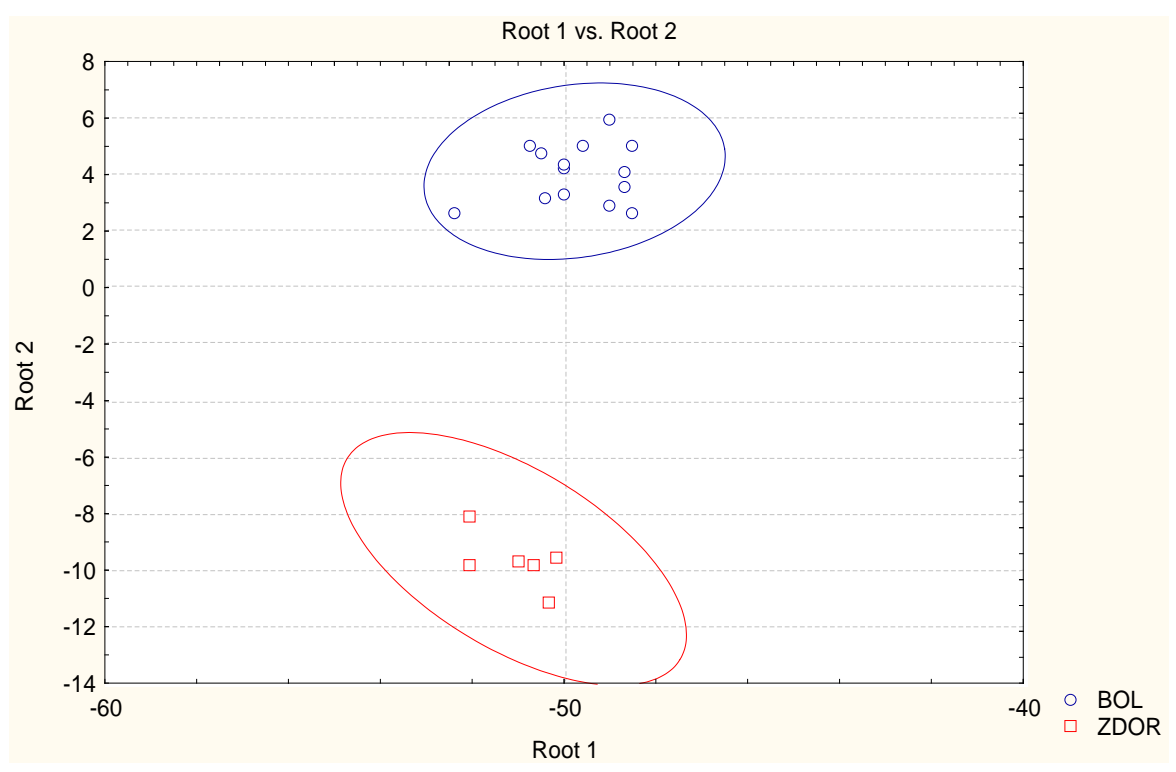

Figure 7. Results of discriminatory analysis applied to E-tongue data. 2D distribution of patterns in the plane of the first and second canonical roots. The data dimensionality reduction technique is Fourier Transform. $M=20 . \circ$ designates glaucoma patients and $\square$, presumably healthy testees.

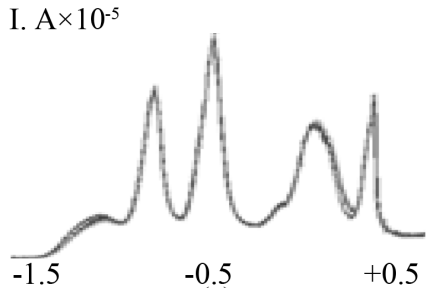

(a)
I. $\mathrm{A} \times 10^{-5}$

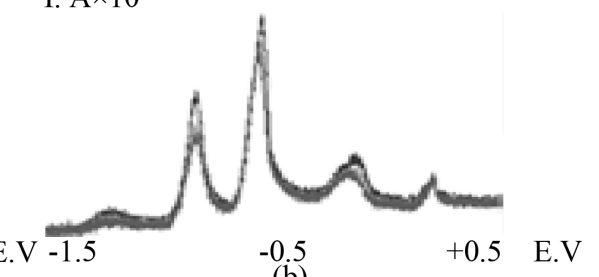

(b)

Figure 8. Voltamperograms (I-current in ampere, E-voltage in volt) of test-system solution (a) and test-system solution with blood serum of glaucoma patients (b).

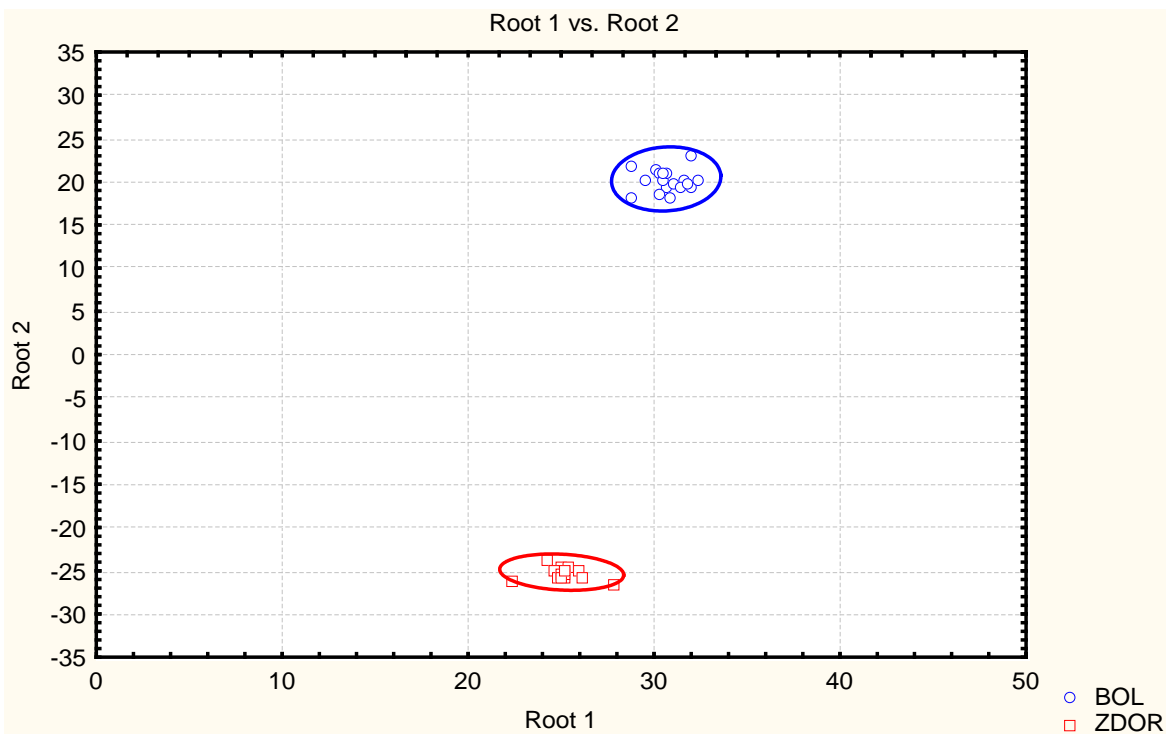

Figure 9. Discriminatory analysis of the E-nose data. 2D distribution of samples in the plane of first and second canonical roots. The data reduction technique is the Principal Components Method. $M=20$. ○—glaucoma patients, $\square-$ presumably healthy testees. 
Table 1. The results of analysis of blood serum samples.

\begin{tabular}{cccc}
\hline \multirow{2}{*}{ Technique } & Sample size (number of measurements) & \multicolumn{2}{c}{ Correct diagnosis, \% } \\
\cline { 3 - 4 } & & healthy & sick \\
\hline E-tongue & 20 & 50 & 64 \\
E-nose & 42 & 67 & 77 \\
\hline
\end{tabular}

probability of 0.95 .

The results show that 10 out of 15 serum samples of presumably healthy people and 21 out of 27 samples of glaucoma patients were discriminated correctly, which amounts to $67 \%$ and $77 \%$, respectively.

Table 1 summarizes the study results.

\section{Discussion}

The statistical processing of the E-tongue and E-nose data shows that the E-nose technique has advantages over the E-tongue technique in terms of both implementation simplicity and recognition reliability. In particular, the E-nose technique implies no preliminary study to determine the dilution rate of serum samples.

As can be seen from Figure 3 and Figure 5, the distance between the centroids of 95\% probability ellipses for E-tongue data is comparable with the average size of the ellipses, whereas the distance for E-nose data is several times larger than the average size of the ellipses.

Despite the low percentage of correct diagnosis (Table 1), Figure 3 and Figure 5 suggest that the more measurements are done the higher discriminability.

\section{Conclusions}

1) It is shown that stripping voltamperometry can be used in electrochemical multi-sensor analysis for blood serum studies by E-tongue and E-nose techniques for the purpose of glaucoma medical screening.

2) Analysis of blood serum samples of glaucoma patients and presumably healthy patients have shown that the E-nose technique is better than E-tongue one in terms of both implementation simplicity and pattern recognition reliability.

\section{References}

[1] Jellum, E., Stokke, O. and Eldjam, L. (1973) Analytical Chemistry, 46, 1099.

[2] D’Amico, A., Di Natale, C., Paolesse, R., et al. (2008) Olfactory Systems for Medical Applications. Sensors and Actuators B: Chemical, 130, 458-465. http://dx.doi.org/10.1016/j.snb.2007.09.044

[3] Roscioni, C. and De Ritis, G. (1968) Ann. Carlo Forlanini, 28, 457.

[4] Pickel, D., Manucy, G. and Walker, D. (2004) Evidence for Canine Olfactory Detection of Melanoma. Applied Animal Behaviour Science, 89, 107-116. http://dx.doi.org/10.1016/j.applanim.2004.04.008

[5] Willis, C.M., Church, S.M., Guest, C.M., et al. (2004) Olfactory Detection of Human Bladder Cancer by Dogs: Proof of Principle Study. British Medical Journal, 329, 712. http://dx.doi.org/10.1136/bmj.329.7468.712

[6] McCulloch, M., Jezierski, T., Broffman, M., et al. (2006) Canine Scent Detection in Early- and Late-Stage Lung and Breast Cancers. Integrative Cancer Therapies, 5, 30-39. http://dx.doi.org/10.1177/1534735405285096

[7] Pelosi, P. and Persaud, K.C. (1988) In Sensors and Sensory Systems for Advanced Robotics. In: Dario, P., Ed., Springer-Verlag, Berlin, 361.

[8] Persaud, K.C. (1992) Electronic Gas and Odour Detectors That Mimic Chemoreception in Animals. TrAC Trends in Analytical Chemistry, 11, 61-67. http://dx.doi.org/10.1016/0165-9936(92)80079-L

[9] Persaud, K.C. and Dodd, G. (1982) Analysis of Discrimination Mechanisms in the Mammalian Olfactory System Using a Model Nose. Nature, 299, 352-355. http://dx.doi.org/10.1038/299352a0

[10] Gardner, J.W. (1991) Detection of Vapours and Odours from a Multisensor Array Using Pattern Recognition Part 1. Principal Component and Cluster Analysis. Sensors and Actuators B: Chemical, 4, 109-115. http://dx.doi.org/10.1016/0925-4005(91)80185-M

[11] Ampuero, S. and Bosset, J.O. (2003) The Electronic Nose Applied to Dairy Products: A Review. Sensors and Actua- 
tors B: Chemical, 94, 1-12. http://dx.doi.org/10.1016/S0925-4005(03)00321-6

[12] James, D., Scott, S.M., Ali, Z. and O’Hare, W.T. (2005) Chemical Sensors for Electronic Nose Systems. Microchimica Acta, 149, 1-17. http://dx.doi.org/10.1007/s00604-004-0291-6

[13] Ganshin, V.M., Fesenko, A.V. and Chebyshev, A.V. (1999) Special Equipment. No. 2. (In Russian)

[14] Dolgopolov, N.V. and Yablokov, M. (2007) Peace and Security. No. 3, 54. (In Russian)

[15] Aleixandre, M., Lozano, J., Gutirerrez, J., et al. (2008) Portable e-Nose to Classify Different Kinds of Wine. Sensors and Actuators B: Chemical, 131, 71-76. http://dx.doi.org/10.1016/j.snb.2007.12.027

[16] Helli, O. and Sia, M. (2004) Qualitative and Quantitative Identification of $\mathrm{H}_{2} \mathrm{~S} / \mathrm{NO}_{2}$ Gaseous Components in Different Reference Atmospheres Using a Metal Oxide Sensor Array. Sensors and Actuators B, 103, 403-408. http://dx.doi.org/10.1016/j.snb.2004.04.069

[17] Thaler, E.R. (2002) The Diagnostic Utility of an Electronic Nose: Rhinologic Applications. Laryngoscope, 112, 15331542. http://dx.doi.org/10.1097/00005537-200209000-00002

[18] Groves, W.A., Zellers, E.T. and Frye, G.C. (1998) Analyzing Organic Vapors in Exhaled Breath Using a Surface Acoustic Wave Sensor Array with Preconcentration: Selection and Characterization of the Preconcentrator Adsorbent. Analytica Chimica Acta, 371, 131-143. http://dx.doi.org/10.1016/S0003-2670(98)00294-3

[19] Di Natale, C., Macagnano, A., Martinelli, E., et al. (2003) Lung Cancer Identification by the Analysis of Breath by Means of an Array of Non-Selective Gas Sensors. Biosensors and Bioelectronics, 18, 1209-1218. http://dx.doi.org/10.1016/S0956-5663(03)00086-1

[20] Cao, W. and Duan, Y. (2006) Breath Analysis: Potential for Clinical Diagnosis and Exposure Assessment. Clinical Chemistry, 52, 800-811. http://dx.doi.org/10.1373/clinchem.2005.063545

[21] Lukovtsev, V.P., Doronin, A.N., Lukovtseva, N.V., Semenov, V.A. and Ganshin, V.M. (2009) Identification of Alkaloids by Stripping Voltamperometries. Electrochemistry, 45, 869-872. (In Russian)

[22] Andreev, V.N., Ganshin, V.M., Doronin, A.N., et al. (2008) Patent of the Russian Federation No. 2375705. (In Russian)

[23] Kolesnichenko, I.I., Ganshin, V.M., Kluev, A.L., et al. (2013) Proceeding of 4th International Scientific and Practical Conference. Publishing House of the Polytechnic University, Saint-Petersburg, 189. (In Russian)

[24] Khalafyan, A.A. (2007) Statistica 6. Statistical Data Analysis. 3rd Edition, Moscow. (In Russian)

\section{Submit or recommend next manuscript to SCIRP and we will provide best service for you:}

Accepting pre-submission inquiries through Email, Facebook, Linkedin, Twitter, etc A wide selection of journals (inclusive of 9 subjects, more than 200 journals)

Providing a 24-hour high-quality service

User-friendly online submission system

Fair and swift peer-review system

Efficient typesetting and proofreading procedure

Display of the result of downloads and visits, as well as the number of cited articles

Maximum dissemination of your research work

Submit your manuscript at: http://papersubmission.scirp.org/ 